\title{
Combining Desmopressin and Docetaxel for the Treatment of Castration-Resistant Prostate Cancer in an Orthotopic Model
}

\author{
ROMAN BASS ${ }^{1}$, DOMENICA ROBERTO ${ }^{1}$, DANIEL ZONGJIE WANG ${ }^{2}$, FERNANDO PENA CANTU ${ }^{2}$, \\ REZA M. MOHAMADI ${ }^{2}$, SHANA O. KELLEY ${ }^{2}$, LAURENCE KLOTZ ${ }^{1}$ and VASUNDARA VENKATESWARAN ${ }^{1}$ \\ ${ }^{1}$ Department of Surgery, Division of Urology, Sunnybrook Health Sciences Centre, \\ University of Toronto, Toronto, ON, Canada; \\ ${ }^{2}$ Department of Pharmaceutical Science, University of Toronto, Toronto, ON, Canada
}

\begin{abstract}
Background/Aim: Desmopressin is a synthetic analogue of the antidiuretic hormone vasopressin. It has recently been demonstrated to inhibit tumor progression and metastasis in breast cancer models. Docetaxel is a chemotherapy agent for castrate-resistant prostate cancer $(C R P C)$. In this study, the ability of CRPC cells to grow and develop in vivo tumors in an animal model was evaluated, in order to investigate the anti-tumor effect of desmopressin in combination with docetaxel. Materials and Methods: The CRPC cell line PC3 was used for orthotopic inoculation in male athymic nude mice. The mice were randomly assigned to one of the four treatment groups: Control, docetaxel, desmopressin or combination therapy. Following the last treatment, tumors were excised and measured. Blood samples were processed for CTC analysis. Results: Docetaxel treatment resulted in a significant reduction in tumor volume compared to control. The combination therapy resulted in even more significant reduction (31.2\%) in tumor volume. There was a complete absence of CTCs in the combination group. Conclusion: Our pilot study demonstrated an enhanced efficacy of docetaxel-based therapy in combination with desmopressin.
\end{abstract}

Docetaxel is a primary chemotherapy agent used for the treatment of Castration-Resistant Prostate Cancer (CRPC) (1, 2). It is a cytotoxic antimicrotubule agent that binds to the $\beta$ tubulin subunit of microtubulin, resulting in stabilization of microtubules and prevention of depolymerization, leading to inhibition of microtubule dynamics, cell-cycle arrest and

Correspondence to: Dr. Vasundara Venkateswaran, Associate Professor, Department of Surgery, Division of Urology, S-120, Sunnybrook Health Sciences Centre, University of Toronto, 2075 Bayview Ave., Toronto Ontario M4N 3M5, Canada. Tel: +1 4164806100 x3127, e-mail: vasundara.venkateswaran@sunnybrook.ca

Key Words: Castration resistant prostate cancer, orthotopic model, prostate, desmopressin, docetaxel. eventually apoptotic cell death $(3,4)$. However, only about $48 \%$ of patients have an objective response to docetaxel treatment with a median survival benefit of 2.5 months. This is accompanied by a serious adverse event rate of $26-29 \%$. A non-toxic agent that is able to enhance the efficacy of chemotherapy without increasing toxicity, would improve the treatment of CRPC. Therefore, a lower dose of docetaxel could be employed, resulting in less toxicity and/or more favorable outcomes. Desmopressin (1-deamino-8-D-arginine vasopressin, also known as DDAVP) is a synthetic analog of the antidiuretic hormone vasopressin, that targets multiple physiological pathways including an oncogenic pathway (5). Desmopressin inhibits plasminogen activator, a key enzyme involved in the activation of matrix metalloproteases resulting in invasion and metastasis. It is a well-tolerated and convenient hemostatic drug used for von Willebrand's disease and related forms of hemophilia. It is also an effective agent in patients with diabetes insipidus and nocturnal diuresis (6-8).

In recent years, our group has focused on the effect of desmopressin in combination with docetaxel in different prostate cancer cell lines in vitro as well as in preclinical models including xenograft animal models $(9,10)$. In contrast, an orthotopic animal model, has several significant advantages compared to xenografts. In particular, orthotopic models have a higher metastatic potential, and likely to result in detectable circulating tumor cells $(11,12)$.

Thus, as 'proof of principle', the aim of this study was to evaluate the effect of desmopressin and docetaxel on in vivo tumor growth and development in an orthotopic animal model using CRPC PC3 cells.

\section{Materials and Methods}

All procedures were carried out in accordance with the Canadian Council of Animal Care (CCAC) regulations and local animal research ethics board procedures and approval. Six-week-old male athymic nude mice (Charles River, QC, Canada) were used for assessment of the combining effect of desmopressin and docetaxel therapy on PC3 tumor growth in an orthotopic model. The Mice were placed under the 
sterile barrier system with constant temperature and humidity as well as experimental conditions in accordance with specific pathogen-free (SPF) standard. Tumor inoculations were done according to the procedure described earlier by J. Pavese et al. (13). Mice were anesthetized with inhalational of isoflurane. The injection site was prepared with iodine-based and alcohol-based solutions and draped in a sterile fashion. Prior to inoculation, animals were given $100 \mu \mathrm{l}$ of meloxicam subcutaneously $(1 \mathrm{mg} / \mathrm{kg})$ as a preemptive analgesia. A 0.5 $\mathrm{cm}$ midline incision was made above the penis and the peritoneal cavity was entered using scissors. The ventral lobe of the prostate gland was identified and the cell suspension $1 \times 106$ PC 3 cells/animal (in $20 \mu \mathrm{l}$ Hank's Balanced Salt Solution) was injected using a syringe with $28 \frac{1}{2} \mathrm{G}$ needle. The muscle layer was closed using 4.0 absorbable vicryl monofilament sutures in a simple interrupted pattern and the skin layer, using sterile $9 \mathrm{~mm}$ staples. During the initial recovery period, mice were maintained under a heating lamp to prevent hypothermia until they recovered fully. The meloxicam dose $(1 \mathrm{mg} / \mathrm{kg})$ was repeated $24 \mathrm{~h}$ following the procedure. The mice were examined daily for tumor formation (visible or palpable tumors) for the duration of the experiment. Body weight of animals was recorded twice weekly. Following 14 days of inoculation, and a visible/palpable tumor, mice were randomly assigned to one of the four treatment groups. Groups (5 animals per group) included: control, $5 \mathrm{mg} / \mathrm{kg}$ docetaxel intraperitoneally, $2 \mu \mathrm{g} / \mathrm{kg}$ body weight desmopressin intravenously, or combination therapy, where desmopressin was administrated $30 \mathrm{~min}$ prior to docetaxel and $24 \mathrm{~h}$ after Each group received treatments biweekly starting 14 days post inoculation, for a total of 3 treatments.

Two weeks following the third treatment, animals were euthanized; tumors excised and measured directly using a vernier caliper. Final tumor sizes and body weight of animals were separately recorded and compared using one-way ANOVA test. Blood was collected by cardiac puncture under anesthesia. The blood samples were then transferred for subsequent CTC analysis.

The CTC capturing was performed by S. Kelley group at the Leslie Dan Faculty of Pharmacy, University of Toronto, Toronto, Canada. In the current study, CTC measurements in whole blood rely on the tagging of cells with magnetic nanoparticles directed toward a surface marker EpCAM as a target $(14,15)$. Nanoparticle-tagged cells were then captured within a fluidic device, where the retaining magnetic force overcomes the drag force that opposes capture. The microfabricated structures were introduced within a fluidic device to create localized pockets of low flow velocity (velocity valleys), regions that strongly favored the accumulation of the targeted cells Figure 1. The collected blood samples were incubated with anti-EpCAM microbeads (antiEpCAM (CD326) microbeads, Miltenyi Biotec, Bergisch Gladbach, North Rhine-Westphalia, Germany) at the ratio of 50:1 (v/v) for $30 \mathrm{~min}$. The incubated samples were sorted in the flow velocity devices at the flow rate of $1 \mathrm{ml} / \mathrm{h}$. The captured cells were fixed and immunostained to distinguish nucleated white blood cells (WBC) from target cells. Cancer cells were distinguished by a triple stain for cytokeratin $\left(\mathrm{CK}^{+}\right.$, Anti-CK19-Alexa Fluor 488; Anti-CK18-FITC; Anti-CK11-Alexa Fluor $488)$, a nuclear stain $\left(\mathrm{DAPI}^{+}\right)$, and by confirmation that they were lacking any staining for CD45 (CD45-, Anti-CD45-APC).

\section{Results}

All four groups of animals completed treatments without major adverse events. No significant toxicity was noted in any group. There was a significant difference $(31 \%)$ in animal body weight gained during the study period between the group that received the combination therapy and the control group (mean \pm SD: $4.5 \pm 0.64$ Gr $v s .3 .08 \pm 0.58$ Gr. $p=0.006$ respectively), while the group receiving docetaxel alone showed no significant difference in gained body weight ( $3.7 \pm 1.33$ Gr. $p=0.37$ ) (Figure 2).

Seven weeks post inoculation, tumor size measurements were performed after all mice were euthanized and tumors were excised. Gross anatomy revealed no visible metastases in the lungs or liver. As seen in Figure 3, the combination treatment of desmopressin with docetaxel caused a slower growth of prostate tumors compared to other treatment groups. The tumors in the combination treatment group were $31.2 \%$ smaller than in the Docetaxel group (mean tumor volume $111.5 \mathrm{~mm}^{3}$ vs. $162.13 \mathrm{~mm}^{3}$, respectively, $\mathrm{p}-0.3$ ). Treatment with docetaxel alone resulted in reduced tumor volume by $27 \%\left(162.13 \mathrm{~mm}^{3}\right)$, whereas the combination treatment by $51 \%\left(111.5 \mathrm{~mm}^{3}\right)$, when compared with the control group $\left(223.46 \mathrm{~mm}^{3}\right)$, that received no treatment $(p=0.09)$.

Representative photographs of animals and tumors post excision are illustrated in Figure 4.

After the animals were sacrificed, their blood was collected by cardiac puncture for CTC count. CTC count in the blood from the combination group was zero compared to mean of 2.0 and 1.5 in the desmopressin and docetaxel groups respectively $(p=0.009)$ (Figures 5 and 6 ).

\section{Discussion}

In previous studies, our team has demonstrated that desmopressin enhances the effect of docetaxel on prostate cancer cell proliferation and migration $(16,17)$. PC 3 and $\mathrm{LNCaP}$ cell lines were used, and anti-proliferative, antimigration and anti-invasive effects on prostate cancer cells in vitro and in vivo were observed. The uPA and its receptor uPAR are expressed in most solid and invasive cancers including PC3 cells (18). Our studies have also demonstrated that desmopressin in combination with docetaxel significantly inhibited the expression of uPA, MMP-2, and MMP-9. These results suggested that desmopressin inhibited cell proliferation and metastasis mediated via the uPA-MMP pathway. The same study revealed that desmopressin enhanced the sensitivity of PC 3 cells to docetaxel in vivo. In a subcutaneous xenograft animal model, the combination treatment resulted in a significant inhibition of tumor growth (9). Further, the additive effect of desmopressin on docetaxel responsiveness in the DU145 cell line was investigated (10). Hoffman A. et al. demonstrated decreased proliferative and migratory potential of DU-145 cells treated with the novel combination both in vitro as well as in a xenograft model of prostate cancer. The mean tumor volume difference between the combination group and the standard therapy with docetaxel alone group was $41.9 \%$ in favor of the combined docetaxel and desmopressin treatment. 


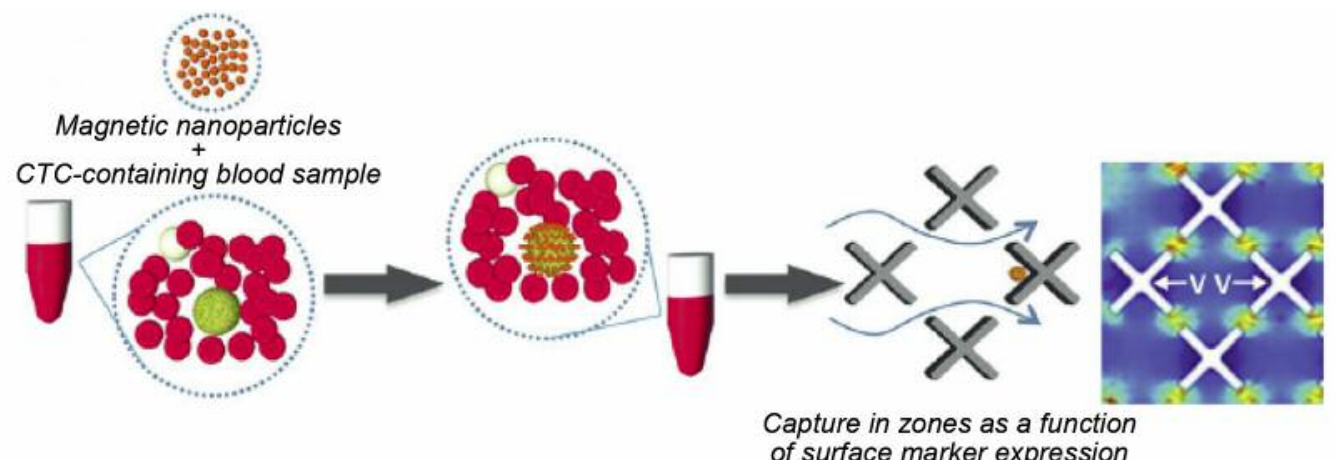

Figure 1. CTCs are tagged with magnetic nanoparticles functionalized with an antibody against the surface marker EpCAM. Labeled CTCs are magnetically captured in the local velocity valleys (VVs) generated by the capture structures. (From "Nanoparticle-Mediated Binning and Profiling of Heterogeneous Circulating Tumor Cell Subpopulations" by R. Mohamadi et al. (15).

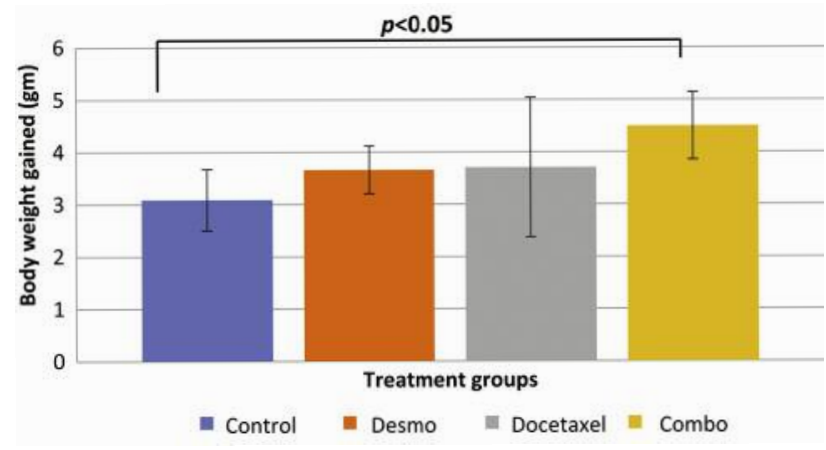

Figure 2. Mean body weight gained throughout the study. Significant difference was noted between the combination and control groups.

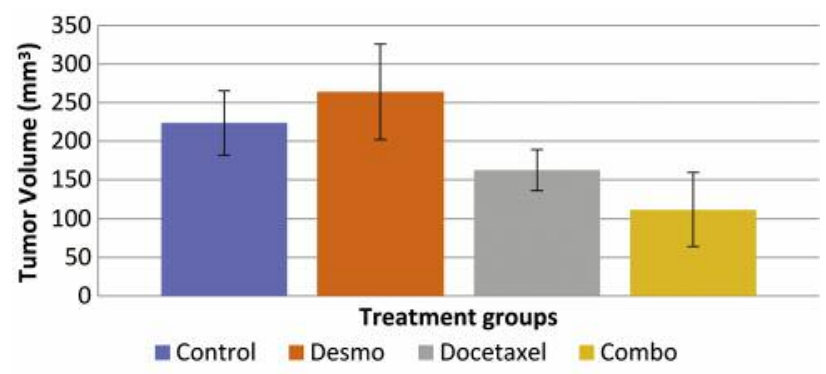

Figure 3. Effects of desmopressin and/or docetaxel treatments on tumor growth using a PC3 orthotopic model. Nude mice were inoculated (intraprostaticly) with $1 \times 10^{6} \mathrm{PC} 3$ cells per mouse. The tumor volumes were measured 7 weeks after the inoculation.

Desmopressin activates the release of endothelial Von Willebrand factor (VWF) by exocytosis. Data from in vitro and in vivo breast cancer models suggest that VWF inhibits tumor cell dissemination and may cause apoptosis of

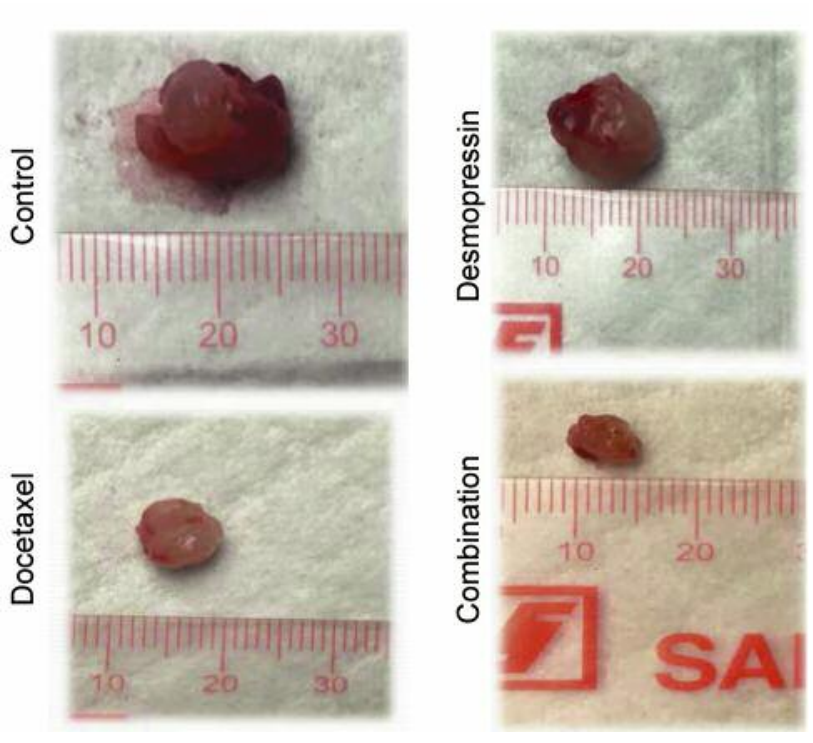

Figure 4. Representative photograph of tumors from each group depicting a reduction in tumor volume with various treatments.

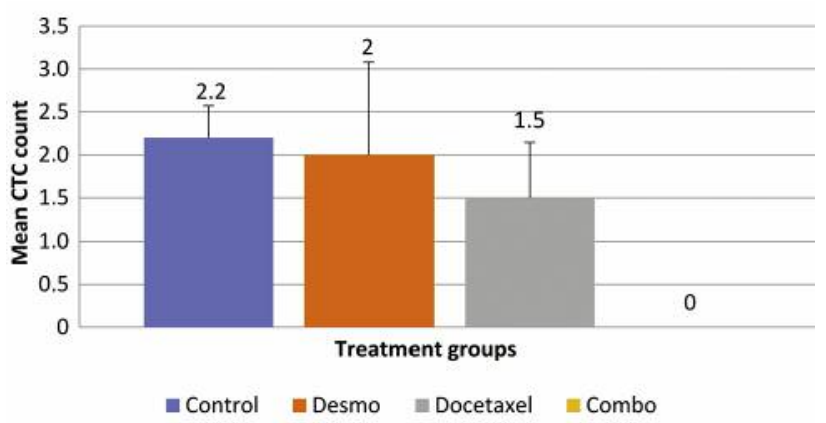

Figure 5. Mean CTC count per 500 ul of whole blood. 

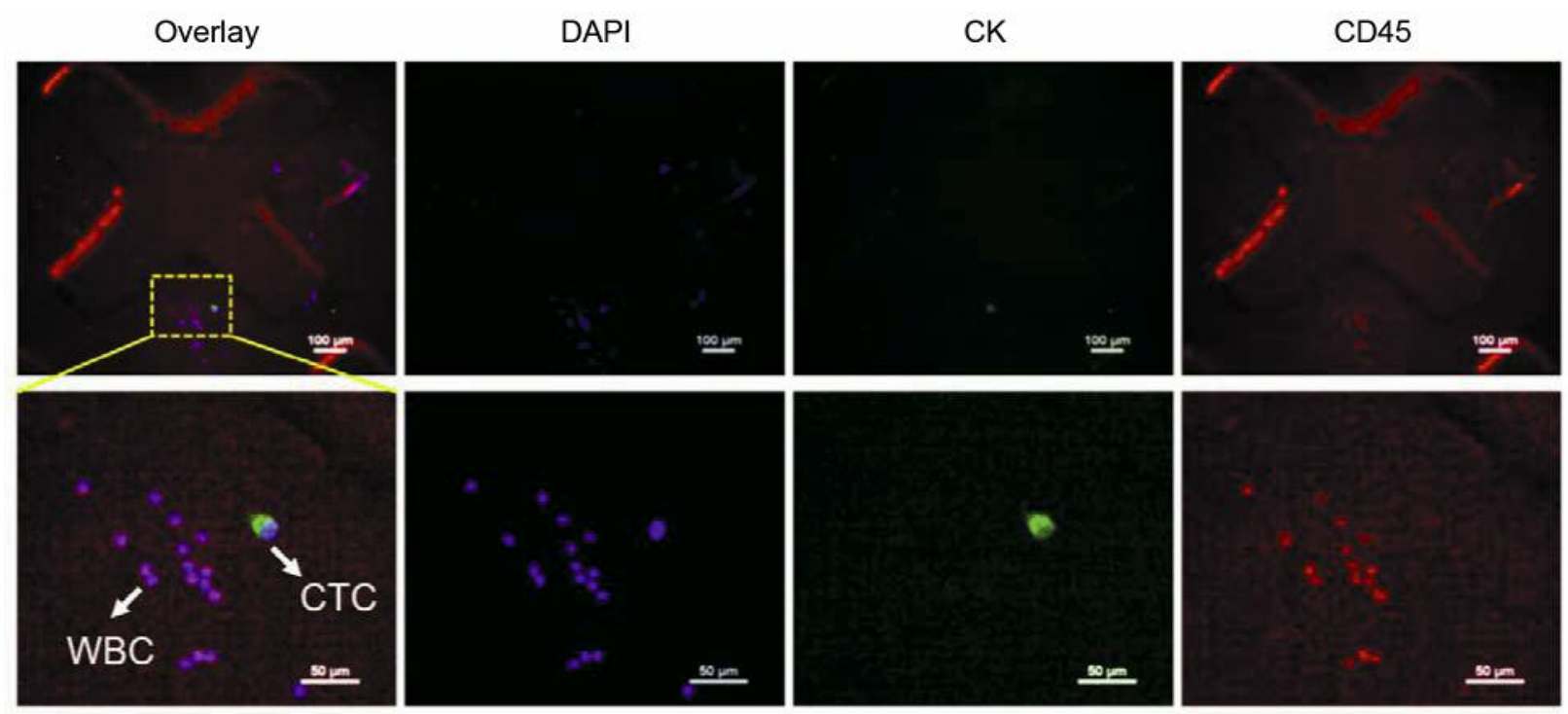

WBC: White blood cell

CTC: Circulating tumor cell
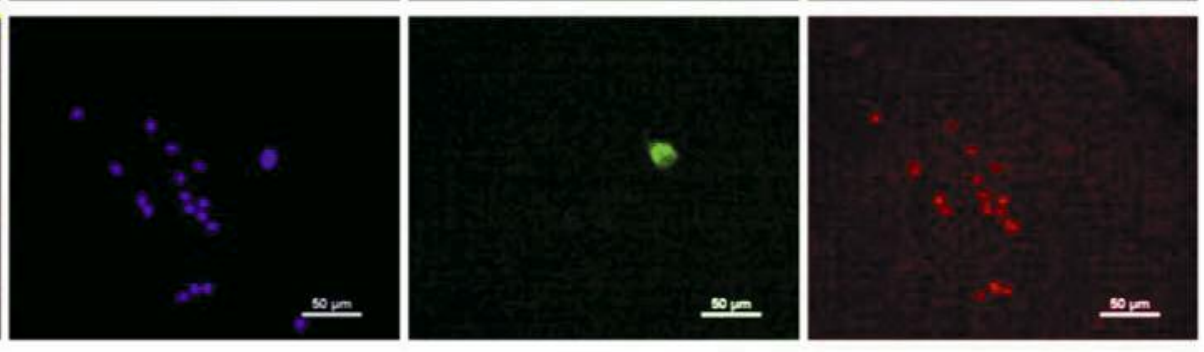

Figure 6. Representative pictures of the captured CTC. Tumor cell has a positive stain for DAPI and CK, but negative for CD45.

micrometastatic foci by exhibiting anti-angiogenic as well as cytostatic effects $(19,20)$.

It is now well known, that migration and invasion are important steps in cancer metastasis. The microenvironment is well documented to influence tumor cell behavior and is capable of stimulating or repressing cell plasticity, proliferation, migration, and invasion $(21,22)$. An orthotopic animal model (compared to an ectopic, usually subcutaneous, site) is more revealing in investigation of novel agents for cancer treatment (23) and for this reason it has been chosen for the current study. Thus, there are several advantages of an orthotopic system. One of the most obvious is that it targets processes in local invasion e.g. inhibition of proteases or interference with the process of angiogenesis $(24,25)$. Another important benefit of the orthotopic models is that they resemble the human conditions better than the subcutaneous xenograft tumor models. It has been shown, for example, that in rodents with primary malignancies (26, 27) hydralazine, which reduces blood flow in transplantable tumors in rodents, was more effective at reducing blood supply to a subcutaneously transplanted murine colon tumor than to the same tumors transplanted orthotopically (28). Kuo et al., using an in vivo model of small-cell lung cancer (SCLC), showed that cisplatin had significant effects against lung tumors, but was ineffective against the same tumors growing subcutaneously (29). The authors concluded that tumors grown orthotopically reflect the clinical effects of drugs on human SCLC more closely than tumors growing subcutaneously. The Fidler group made the equally valid point that human colon xenografts growing subcutaneously in nude mice often respond to dox, whereas human colon cancer does not (30). Based on these and other studies, orthotopically-transplanted tumors are considered more appropriate models for investigating drug effects than subcutaneous transplanted tumor models.

In our present study using the orthotopic model, desmopressin treatment was administered by two intravenous injections covering a 24-h time period following chemotherapy treatment. It is demonstrated that combining desmopressin with docetaxel caused a reduction in tumor growth of this aggressive castrate-resistant prostate cancer cells by $51 \%$ compared to placebo and by $31 \%$ compared to standard chemotherapy agent alone. Reduction in tumor size is likely mediated through several mechanisms, e.g. decreased proliferation and migration via the uPA-MMP pathway, apoptosis induction and reduced angiogenesis due to Von Willebrand factor release. Research attempting to reduce cancer cell proliferation and metastasis by various vasopressin analogues is also ongoing in the field of breast cancer, and the results are encouraging (31). Combining desmopressin during chemotherapy for CRPC patients could likely increase the efficacy of docetaxel and reduce toxicity.

Another attractive advantage of the orthotopic model is its ability to deliver viable malignant cells i.e. circulating tumor cells (CTCs), into the bloodstream in contrast to the subcutaneous tumor model (32). Dissemination of tumor cells into peripheral blood is the first step of metastases (3334) and the presence of CTCs in advanced stage prostate 
cancer patients has been correlated with poor prognosis (35). It has been shown that CTC enumeration serves as a surrogate biomarker of therapeutic response in several tumor types $e . g$. lung, breast and prostate (36-38).

The analysis of blood from the control, desmopressin alone and docetaxel alone groups of animals revealed detectable CTCs in each of these groups, (range=1-5 per $500 \mu \mathrm{l}$ of whole blood), however, no CTCs were detected in the blood from mice treated with the combination therapy.

There are limitations to the current study. In this proof-ofprinciple study, our theory was in modest group sizes that resulted in low power to detect differences between groups in terms of final tumor size. Low numbers of CTCs detected in some animals in our study prevented us from making a robust conclusion about the efficacy of the desmopressindocetaxel combination at eradicating CTCs.

\section{Conclusion}

Combining desmopressin and docetaxel resulted in a considerable reduction in tumor size, as determined using an in vivo orthotopic animal model, thereby contributing to the enhanced efficacy of docetaxel-based therapy compared to either treatment alone. The combination therapy resulted in a complete absence of CTCs compared to docetaxel alone. Clinical trials confirming these observations are currently underway.

\section{Conflicts of Interest}

The Authors declare that they have no conflicts of interest regarding this study.

\section{References}

1 Petrylak DP, Tangen CM, Hussain MH, Lara PN Jr, Jones JA, Taplin ME, Burch PA, Berry D, Moinpour C, Kohli M, Benson MC, Small EJ, Raghavan D and Crawford ED: Docetaxel and estramustine compared with mitoxantrone and prednisone for advanced refractory prostate cancer. N Engl J Med 351: $1513-$ 1520, 2004.

2 Tannock IF, de Wit R, Berry WR, Horti J, Pluzanska A, Chi KN, Oudard S, Théodore C, James ND, Turesson I, Rosenthal MA and Eisenberger MA; TAX 327 Investigators: Docetaxel plus prednisone or mitoxantrone plus prednisone for advanced prostate cancer. N Engl J Med 351: 1502-1512, 2004.

3 Ramaswamy B and Puhalla S: Docetaxel: A tubulin-stabilizing agent approved for the management of several solid tumors. Drugs Today (Barc) 42: 265-279, 2006.

4 Katsumata N: Docetaxel: An alternative taxane in ovarian cancer. Br J Cancer 89: S9-S15, 2003.

5 Ripoll GV, Garona J, Pifano M, Farina HG, Gomez DE and Alonso DF: Reduction of tumor angiogenesis induced by desmopressin in a breast cancer model. Breast Cancer Res Treat 142: 9-18, 2013.
6 Mannucci PM: Desmopressin (DDAVP) in the treatment of bleeding disorders, the first 20 years. Blood 90: 2515-2521, 1997.

7 Richardson DW and Robinson AG: Desmopressin. Ann Intern Med 103: 228-239, 1985.

8 Vande Walle J, Stockner M, Raes A and Norgaard JP: Desmopressin 30 years in clinical use: a safety review. Curr Drug Saf 2: 232-238, 2007.

9 Sasaki H, Klotz LH, Sugar LM, Kiss A and Venkateswaran V: A combination of Desmopressin and Docetaxel inhibit cell proliferation and invasion mediated by urokinasetype plasminogen activator (uPA) in human prostate cancer cells. Biochem Biophys Res Commun 464: 48-854, 2015.

10 Hoffman A, Sasaki H, Roberto D, Mayer MJ, Klotz LH and Venkateswaran V: Effect of Combination therapy of Desmopressin and Docetaxel on prostate cancer cell (DU145) proliferation, migration and tumor growth. J Cancer Biol Therap 1: 129-136, 2016.

11 Rembrink K and Romijn JC: Orthotopic implantation of human prostate cancer cell lines: a clinically relevant animal model for metastatic prostate cancer. The Prostate 31: 168-174, 1997.

12 Bibby MC: Orthotopic models of cancer for preclinical drug evaluation: advantages and disadvantages. Eur J Cancer 40: 852857, 2004.

13 Pavese J, Ogden IM and Bergan RC: An Orthotopic Murine Model of Human Prostate Cancer Metastasis. J Vis Exp 79: 50873, 2013

14 Mohamadi RM, Besant JD, Mepham A, Green B, Mahmoudian L, Gibbs T, Ivanov I, Malvea A, Stojcic J, Allan AL, Lowes LE, Sargent EH, Nam RK and Kelley SO: Nanoparticle-mediated binning and profiling of heterogeneous circulating tumor cell subpopulations. Angew Chem Int Ed Engl 54: 139-143, 2015.

15 Muhanna N, Mepham A, Mohamadi RM, Chan H, Khan T, Akens M, Besant JD, Irish J and Kelley SO: Nanoparticle-based sorting of circulating tumor cells by epithelial antigen expression during disease progression in an animal model. Nanomedicine 11: 1613-1620, 2015.

16 Sasaki H, Klotz LH, Sugar LM, Kiss A and Venkateswaran V: A combination of Desmopressin and Docetaxel inhibit cell proliferation and invasion mediated by urokinasetype plasminogen activator (uPA) in human prostate cancer cells. Biochem Biophys Res Commun 464: 848-854, 2015.

17 Hoffman A, Sasaki H, Roberto D, Mayer MJ, Klotz LH and Venkateswaran V: Effect of Combination therapy of Desmopressin and Docetaxel on prostate cancer cell (DU145) proliferation, migration and tumor growth. J Cancer Biol Therap 1: 129-136, 2016.

18 Festuccia C1, Dolo V, Guerra F, Violini S, Muzi P, Pavan A and Bologna M: Plasminogen activator system modulates invasive capacity and proliferation in prostatic tumor cells. Clin Exp Metastasis 16: 513-528, 1998.

19 Ripoll GV, Garona J, Pifano M, Farina HG, Gomez DE and Alonso DF: Reduction of tumor angiogenesis induced by desmopressin in a breast cancer model. Breast Cancer Res Treat 142: 9-18, 2013.

20 Alonso DF, Skilton G, Farías EF, Bal de Kier Joffé E and Gomez DE: Antimetastatic effect of desmopressin in a mouse mammary tumor model. Breast Cancer Res Treat 57: 271-275, 1999.

21 Fidler IJ: The organ microenvironment and cancer metastasis. Differentiation 70: 498-505, 2002. 
22 Sottnik JL, Zhang J, Macoska JA and Keller ET: The PCa tumor microenvironment. Cancer Microenviron 4: 283-297, 2011.

23 Stephenson RA, Dinney CP, Gohji K, Ordonez NG, Killion JJ and Fidler IJ: Metastatic model for human prostate cancer using orthotopic implantation in nude mice. J Natl Cancer Inst 84: 951-957, 1992.

24 Yang M, Jiang P, Sun FX, Hasegawa S, Baranov E, Chishima T, Shimada H, Moossa AR and Hoffman RM. A fluorescent orthotopic bone metastasis model of human prostate cancer. Cancer Research 59: 781-786, 1999.

25 Rosol TJ, Tannehill-Gregg SH, LeRoy BE, Mandl S and Contag CH: Animal models of bone metastasis. Cancer 97: 748-757, 2003.

26 Chan RC, Babbs CF, Vetter RJ and Lamar CH: Abnormal response of tumor vasculature to vasoactive drugs. J Natl Cancer Inst 72: 145-150, 1984.

27 Field SB, Needham S, Burney IA, Maxwell RJ, Coggle JE and Griffiths JR: Differences in vascular responses between primary and transplanted tumours. Br J Cancer 63: 723-726, 1991.

28 Cowen SE, Bibby MC and Double JA: Characterisation of the vasculature within a murine adenocarcinoma growing in different sites to evaluate the potential of vascular therapies. Acta Oncol 43: 357-360, 1995.

29 Kuo TH, Kubota T, Watanabe M, Furukawa T, Kase S, Tanino H,Saikawa Y, Ishibiki K, Kitajima M and Hoffman RM: Sitespecific chemosensitivity of human small-cell lung carcinoma growing orthotopically compared to subcutaneously in SCID mice: the importance of orthotopic models to obtain relevant drug evaluation data. Anticancer Res 13: 627-630, 1993.

30 Fidler IJ, Wilmanns C, Staroselsky A, Radinsky JR, Dong Z and Fan D: Modulations of tumor cell response to chemotherapy by the organ environment. Cancer Metastasis Rev 13: 209-222, 1994.

31 Iannucci NB, Ripoll GV, Garona J, Cascone O, Ciccia GN, Gomez DE and Alonso DF: Antiproliferative effect of 1deamino-8-darginine vasopressin analogs on human breast cancer cells. Future Med Chem 3: 1987-1993, 2011.
32 Glinskii AB, Smith BA, Jiang P, Li X-M, Yang M, Hoffman RM and Glinsky GV: Viable circulating metastatic cells produced in orthotopic but not ectopic prostate cancer models. Cancer Res 63: 4239-4243, 2003.

33 Zhou J, Hu L, Yu Z, Zheng J, Yang D, Bouvet M and Hoffman RM: Marker expression in circulating cancer cells of pancreatic cancer patients. J Surg Res 171: 631-636, 2010.

34 Morgan TM, Lange PH and Vessella RL: Detection and characterization of circulating and disseminated prostate cancer cells. Front Biosci 12: 3000-3009, 2007.

35 Moreno JG, Miller MC, Gross S, Allard WJ, Gomella LG and Terstappen LW: Circulating tumor cells predict survival in patients with metastatic prostate cancer. Urology 65: 713-718, 2005.

36 Koinis F, Agelaki S, Karavassilis V, Kentepozidis N, Samantas E, Peroukidis S,Katsaounis P, Hartabilas E, Varthalitis II, Messaritakis I, Fountzilas G, Georgoulias V and Kotsakis A: Second-line pazopanib in patients with relapsed and refractory small-cell lung cancer: a multicentre phase II study of the Hellenic Oncology Research Group. Br J Cancer 117: 8-14, 2017.

37 Scher HI, Heller G, Molina A, Attard G, Danila DC, Jia X, Peng W, Sandhu SK, Olmos D, Riisnaes R, McCormack R, Burzykowski T, Kheoh T, Fleisher M, Buyse M and de Bono JS: Circulating tumor cell biomarker panel as an individual-level surrogate for survival in metastatic castration-resistant prostate cancer. J Clin Oncol 33: 1348-1355, 2015.

38 Friedlander TW and Fong L: The end of the beginning: Circulating tumor cells as a biomarker in castration-resistant prostate cancer, J Clin Oncol 32: 1104-1106, 2014.

Received November 12, 2018

Revised November 24, 2018

Accepted November 27, 2018 